\title{
BMJ Open To work despite chronic health conditions: a qualitative study of workers at the Swedish Public Employment Service
}

Carina Hjärtström, ${ }^{1,2}$ Annika Lindahl Norberg, ${ }^{1,3}$ Gun Johansson, ${ }^{1,3}$ Theo Bodin ${ }^{1,3}$

To cite: Hjärtström C, Lindahl Norberg A, Johansson G, et al. To work despite chronic health conditions: a qualitative study of workers at the Swedish Public Employment Service. BMJ Open 2018;8:e19747. doi:10.1136/ bmjopen-2017-019747

- Prepublication history and additional material for this paper are available online. To view these files, please visit the journal online (http://dx.doi. org/10.1136/bmjopen-2017019747).

Received 27 September 2017 Revised 14 March 2018 Accepted 20 March 2018
Check for updates

${ }^{1}$ Unit of Occupational Medicine, Institute of Environmental Medicine, Karolinska Institutet, Stockholm, Sweden

${ }^{2}$ Department of Rehabilitation to Work, Arbetsformedlingen, Västerås, Sweden

${ }^{3}$ Center for Occupational and Environmental Medicine, Stockholms Lans Landsting, Stockholm, Sweden

Correspondence to DrTheo Bodin; theo.bodin@ki.se

\section{ABSTRACT}

Objectives Achieving a sustainable, healthy and long working life is key prerequisite for meeting the demographic challenge posed by an ageing population so that more people can work on into their later years. The objective of this study is to explore the relationship between work and chronic health conditions in a group of employees aged 50-64 years with a focus on factors that enable them to continue to work.

Methods Ten white-collar workers with one or more chronic health conditions at the Swedish Public Employment Service participated in the study. A qualitative method with semistructured in-depth interviews was used to collect data.

Results and conclusions This study shows that factors enabling people with chronic health conditions to work include adaptation of the work situation by task-shifting as well as provision of physical aids. Our study suggest that the changes often come at the employee's initiative; hence, there is potential for greater involvement from the employer, healthcare agencies and the social insurance fund in making it easier for employees to adapt their work situation and in providing information regarding available support. It confirms findings in earlier studies that health plays an important part and also that self-confidence and motivation are significant factors contributing to workers being able and wanting to continue working.

\section{BACKGROUND}

Achieving a sustainable, healthy and long working life is key prerequisite for meeting the demographic challenge posed by an ageing population. By 2060 , there will be only two people of working age (15-64 years) in the European Union for every person over 65 years, compared with a ratio of 4-1 today. This will likely lead to a shortage in the labour force and could result in slower economic growth. ${ }^{1}$ Sweden has one of the highest rates of employment in the world, including among older workers. In spite of this, $14 \%$ of all employees between the ages of 50 years and 64 years say that, regardless of the state of their health, they do not think that they will be able to work until the normal retirement

\section{Strengths and limitations of this study}

- All participants in this study has been interviewed by a single person with long work experience in occupational health, especially rehabilitation.

- It was evident that the study reached an acceptable saturation with regards to factors related to continuation of work and support needs.

- The description of the study population includes detailed information including self-perceived health and workability index.

- A limitation is that the invitation was sent by the employer, and critical voices might have had second thought on participating.

- Adherence to the Consolidated criteria for Reporting Qualitative research guidelines has been implemented from the start in order to meet the quality standards for both publishing and inclusion in future reviews.

age. ${ }^{2}$ Early retirement from work is a complex process that takes place over time and is dependent on numerous different circumstances at both a personal and society levels, where health is one of the most important factors. ${ }^{3}$

The number of people with chronic health conditions is rising. In Sweden, more than 650000 people report that health conditions such as impaired hearing, chronic pain, impaired mobility, mental disabilities, cardiovascular conditions or allergies has a negative effect on their work ability. More than $60 \%$ of those with disabilities without employment think they could perform a job if they were supported with some form of adaptations at work. ${ }^{4}$ A Dutch study has shown that work adaptions are associated with a decrease in sick leave but are estimated to be underused opportunities for people with chronic disease. ${ }^{5}$ Another study indicates that people with impaired health often end their working life earlier than desired. ${ }^{367}$ A systematic review indicates that factors that enable people with 
chronic musculoskeletal pain to stay at work are different kinds of work adjustment, such as improved ergonomics, and social support, but the evidence is weak. ${ }^{8}$ People with chronic health conditions have an increased risk of early retirement. ${ }^{9}$ There is a great potential to maintain these groups in working life if we have a better understanding of conditions enabling this. However, there are only a few studies that are investigating factors in the work environment that plays a key role in encouraging people with chronic health conditions to participate in the labour market. There is also a lack of research into how workplaces can adapt to and meet the needs and requirements of employees with chronic health conditions. ${ }^{3}$ Employers also report lack of knowledge about disability and possible adaptions at work. ${ }^{10}$ In light of this, it would seem important to analyse the experience of people with chronic ill-health conditions in terms of their working life and work environment, as well as which factors enables them to continue work.

The aim of this study is to explore the relationship between work and chronic ill-health in a group of public sector employees with a focus on factors that enable them to continue to work.

\section{MATERIALS AND METHODS \\ Preparation of manuscript}

The Consolidated criteria for Reporting Qualitative research (COREQ) checklist designed for qualitative studies, in-depth interviews and focus groups has been used to ensure that all the components that should be included are described in the existing study. ${ }^{11}$

\section{Patient and public involvement}

Patients and or public were not involved in development of this study. The results of the study were disseminated to study participants through a personal copy of a Swedish draft of this paper.

\section{Study population and recruitment}

All the study participants worked for the Swedish Public Employment Service, which is a government agency whose main task is to help match job-seekers with employers.

An email invitation was sent via the employer to all staff in three offices during the period December 2016January 2017. An additional email was sent out with a reminder. Some offices mentioned the study at workplace meetings and put the recruitment letter in the employees' mailboxes.

The recruitment letter specified the following inclusion criteria: (A) permanent employee as an administrator at the Swedish Public Employment Service, (B) aged 50-64 years and (C) one or more chronic health conditions since at least 1 year back.

Those interested in participating in the study were requested to contact the studies' first author via email or telephone. An assessment was made at the initial contact as to whether the specified selection criteria were met before a meeting was arranged for a face-to-face interview. The aim was to interview between 8 and 12 participants. The interviews took place between January and March 2017.

\section{Interviews}

A qualitative method with semistructured in-depth interviews was used to collect data. The interviews were conducted at the study participants' respective workplaces during working hours. The study participants chose where and when the meeting would be held. One of the interviews was conducted via Skype. All interviews were conducted individually, with one interview per study participant. The interviews were conducted by the lead author, who is a woman, master's student and physiotherapist, with more than 7 years of work experience in vocational rehabilitation.

The interviews lasted between $45 \mathrm{~min}$ and $75 \mathrm{~min}$. There were also a few minutes where the interviewer introduced herself, the study and its purpose and also asked the participant to sign the consent form. The interviews ended with a summary by the interviewer. Field notes were not made during the interview.

An interview guide approach was used for the interviews (see online supplementary appendix 1). The interview guide was designed by the study authors and was used in a pilot interview and thereafter adapted to its final form .

Furthermore, the interviews ended with four-rating scales relating to work ability, general state of health and motivation to work. The purpose of the rating scales was to give a fuller description of the study participants. The ratings were done at the end of the interviews to avoid interference with the interview. The following four questions were used to survey self-perceived work ability, motivation and health: (1) how would you assess your current work ability compared with when it was at its peak on a scale from 0 to 10 ? $(0=$ cannotwork at all, $10=$ workability when it is $/$ was at its peak); (2) thinking about your health, do you think that you can still be doing your current job in 2years? (No, I don't; I don't really know; and Yes, I definitely will be); (3) how important is work to you on a scale from 1 to 10 ? $(0=$ not at all important, $10=$ extremelyimportant; and (4) how would you assess your general state of health? (very good, good, reasonable, poor and very poor).

\section{Analysis}

The interviews were recorded, transcribed verbatim and coded by the lead author. Inductive thematic analysis was used for analysis. ${ }^{12}$ The entire analysis covered six phases: reading and rereading the transcripts, initial coding, identifying subthemes and themes, reviewing the themes in relation to the coded data, defining and describing the themes and finally producing a synthesis of the results in this paper. The analysis was inductive, and the structure of the initial coding was guided by the study aim. Data extracts related to the subject matter were identified, condensed and coded. Subsequently, codes were organised in preliminary themes. These were reviewed 
and revised in dialogue with the uncondensed interview data, emerging into a final theme structure. Due to the manageable amount of data, specific analysis software was not used and instead MS Word table was used to keep the structure of the analysis. The analysis was based on the study participants' manifest statements. The analysis was performed by the lead author who, throughout the analysis process, discussed the coding and the themes with the coauthors. The rest of the research team comprises a doctor, sociologist and psychologist, who all hold PhDs. Transcriptions were not sent to the informants.

Quotes from the study participants, which are presented in the results section, appear in italics. The word order has sometimes been changed, and they have been shortened to make them easier to read. Some words have been removed to avoid identification.

\section{RESULTS}

\section{Description of the study population}

Ten employees from three different offices expressed an interest in the study. They all met specified criteria and participated in the study. Informants' characteristics are summarised in table 1 . The most frequently occurring chronic health conditions were long-term pain conditions, hearing loss, state of fatigue, as well as cardiovascular diseases. Four study participants reported one condition, two persons two conditions and the remaining four reported three or more. One person was on sick leave $25 \%$ of the time. Current work ability, compared with when it was at its best, was high (median=8) for all participants except one individual who indicated 2 on the scale from 0 to 10 . In terms of forecasting their work ability in 2 years from now, in light of their current state of health, 7 out of 10 study participants reckoned they were sure that they could do their current job in 2 years if the same circumstances applied. Most of them considered their general state of health to be fairly good or acceptable, in spite of enduring restrictions for many years due to chronic health conditions. Work was considered to be important in many respects by all the study participants.

\section{General observations of factors related to continuation of work despite having a chronic health condition}

The condensation of the interviewes produced 13 subthemes that could further be grouped into five main themes. The subthemes and main themes are presented in table 2, and a detailed presentation of example quotes and condensations are found in table 1 in the online supplementary appendix 1 . Almost all of the study participants reported different types of adaptions as important factors to enable continuation of work. In the cases when adaptations of work had not taken place for one reason or the other, this was perceived as a problem. Furthermore, it was also evident that the adaptations that had taken place in most cases came at the informants' own initiative. Although the study participants who had informed their employer about their health condition experienced
Table 1 Background information and characteristics of informants $(n=10)$

\begin{tabular}{|c|c|}
\hline \multicolumn{2}{|l|}{ Sex } \\
\hline Men & 2 \\
\hline Women & 8 \\
\hline \multicolumn{2}{|l|}{ Age } \\
\hline Median (range) & $59.5(51-63)$ \\
\hline \multicolumn{2}{|l|}{ Educational level } \\
\hline High school or lower & 4 \\
\hline University & 6 \\
\hline \multicolumn{2}{|l|}{ Health status } \\
\hline Very poor & 0 \\
\hline Poor & 0 \\
\hline Reasonable & 5 \\
\hline Good & 5 \\
\hline Very good & 0 \\
\hline \multicolumn{2}{|c|}{ Years with chronic health condition } \\
\hline$>5$ & 2 \\
\hline$>10$ & 8 \\
\hline \multicolumn{2}{|c|}{ Most common chronic health conditions } \\
\hline \multicolumn{2}{|c|}{ Chronic pain condition } \\
\hline \multicolumn{2}{|l|}{ Hearing loss } \\
\hline \multicolumn{2}{|l|}{ Burnout/chronic fatigue } \\
\hline \multicolumn{2}{|l|}{ Cardiovascular disease } \\
\hline \multicolumn{2}{|l|}{ Employment activity } \\
\hline Part-time & 3 \\
\hline Full time & 7 \\
\hline \multicolumn{2}{|l|}{ Years at current employer } \\
\hline \multicolumn{2}{|l|}{$8-30$} \\
\hline \multicolumn{2}{|l|}{ Importance of work $(1-10)$} \\
\hline Median (range) & $8(5-9)$ \\
\hline \multicolumn{2}{|l|}{ Work ability $(0-10)$} \\
\hline Median (range) & $8(2-9)$ \\
\hline \multicolumn{2}{|c|}{$\begin{array}{l}\text { Will be working at the same job in } 2 \text { years } \\
\text { from now }\end{array}$} \\
\hline No & 0 \\
\hline Don’t know & 3 \\
\hline Yes, definitely & 7 \\
\hline
\end{tabular}

support, most participants had chosen not to tell the employer. Work was perceived to promote health and as a way to reduce the impact of the chronic condition on quality of life, contributing to social cohesion and sense of purpose.

\section{Adaptation of work}

Physical adaptation/aid, such as an adapted chair, an adjustment made to a computer workstation or getting their own separate office were mentioned as significant and important requirements for coping with work by 
Table 2 Thematic analysis of factors enabling work despite chronic health conditions

\begin{tabular}{ll}
\hline Subtheme & Main theme \\
\hline $\begin{array}{l}\text { Physical adaptation/aid } \\
\text { Modifications to work tasks }\end{array}$ & Adaptation \\
Changes in approach to work & \\
Work-life balance & Lifestyle \\
Physical activity & \\
Acceptance & Confidence in one's \\
Decision latitude & own abilities \\
Intellectual stimulus & Motivation \\
Social cohesion & \\
Sense of purpose & \\
Superiors & Support from others \\
Healthcare & \\
Social security & \\
\hline
\end{tabular}

the participants who had received this type of support. Several study participants had the perception that their employer was generous with providing physical aids if they were asked to do so.

There are no problems getting help. I've always had good gadgets, a suitable chair, a Mousetrapper mouse and other devices to help me at my workstation. I'm eternally grateful for this. Participant number 6

However, requests for aids were seldom made as they did not know what they should ask for, or they did not take the time to ask for it. As one of the respondents witnessed, the difficulty in getting an own office appeared to be a major obstacle to cope with work:

I find it extremely hard to concentrate and take in what I'm doing when there are several of us in an office. Participant number 7

Modifications to work tasks resulted in fewer physical and mental demands. Examples of these modifications included fewer but more specialised tasks, less customer contact, greater opportunity for own planning and, in some cases, less administration. Study participants who had adapted their work tasks also found it contributing to a better work-life balance. A change in the approach to work, based on work arrangements and suitable strategies, played a significant role in making work easier. Strategies that emerged included reorganising work through introduction of flexitime and remote working as well as changing details such as varying posture while working and taking more frequent breaks. Two of the participants summarise both changes in work content and organisation:

I used to have greater responsibility in my job, but I felt that it got too much for me. I needed to change the tasks I did for the good of my health. This means that what works for me now is less responsibility, flexitime and I can manage my time better. I now enjoy my job too! Participant number 3
I don't need to go off sick. If my work allows it, I can work flexitime and go home earlier that day to rest. And I can now also plan my new work tasks better. Participant number 10

Although the participants found their employers to be supportive in general, they sometimes perceived no sense of urgency or well-established routines to go about adjusting work. One participant said that the process of getting adaptations made to both equipment and tasks was both complicated, time-consuming and aggravating the health condition:

I would have avoided a great deal of stomach-ache if it hadn't been so complicated. Because there is actually mental stress involved as well. The whole thing took a good year. If it had gone a bit more quickly, I might have perhaps been in a better state than I am now. Participant number 4

\section{Lifestyle}

Physical activity and achieving work-life balance seemed to be important elements in terms of coping better with work increased well-being and maintained work ability. Work-life imbalance had prompted participants to make changes both at work and at home. Reducing working time, changing work content to both less demanding tasks and a decrease in amount of work were all ways of attaining a better work-life balance. At home, some of the participants contemplated to hire a maid in order to be able to keep working. However, in one case, combining continued work at the agency and having a personal life seemed to be utopian:

If I could modify my current work more, I think I can work at 67 , because I think the job is fun. Now I just feel I'm working, going home, sitting and doing nothing and then I'm going to bed. I have no energy to exercise or invite friends, I can't even think of it. But I've actually searched for another job, [laughing], I'm 63 years old and have searched for another job! Participant number 9

The end of the quote above illustrates how the notion of being older with a chronic health condition limits one's options in attaining work-life balance. The only resolve for some seemed to reach retirement age through part-time work.

I'll be 63 soon. I have just started thinking about changing my work situation, maybe decrease working hours. I have not thought so before, but now the work takes so much energy and removes so much from my private life. I have no energy for my grandchildren nor my home, that's how it is. Participant number 3

Physical activity and leisure activities were seen by many as ways to improve their health, both physical and mental, thereby enabling them to cope with work better. Leisure activity was a way of recharging the batteries and relaxing 
mentally, which seemed to be especially important for jobs involving a high level of mental stress. Conversely, in those cases where participants could not do any physical activity, they felt it contributed to a deterioration in their condition:

One thing that's extremely important is that if I don't move about, I feel worse. A gym class and yoga are very important, just as important as the medication I take. Participant number 10

\section{Confidence in one's own abilities}

Confidence was reflected in the study participants' own view of their condition, their acceptance of it and of a notion that they could influence their situation.

Acceptance of the state of their health was prominent among the interviewees. In spite of the restrictions that the disease entailed, most of them voiced the attitude 'when life gives you lemons you make lemonade' and that their situation could have been worse. As one participant said:

I'm almost constantly in pain, but you still learn to live with it somehow. Participant number 9

Confidence in their own ability was perceived to be high, in spite of the tough conditions they endured, as one study participant put it:

I couldn't keep doing the job I was doing then, when I was very ill, but when I got better, I wanted this job $100 \%$ and everyone said that I was mad... But I said that it was maybe something that I could definitely do. Otherwise, I might as well stop. Participant number 7

Perceived adjustment latitude, in terms of the ability to change their work environment and work situation, was a common feature. Overall, everyone felt that they could influence their situation in some way, if they wanted:

If there's something wrong, I fix it. I don't just sit there and wait for someone else to do something. Participant number 1

\section{Motivation}

Even though some participants encountered major difficulties due to their condition, they expressed a strong motivation to work and find solutions enabling them to continue their working life. Intellectual stimulus, meaning interesting, varied and challenging work tasks, was regarded as important motivational factors.

I'm lucky that I think I've got a job that I enjoy and find interesting. Otherwise, I would have gone home a long time ago and gone on sick leave. Participant number 4

Just as important motivational factor was the social dimension of work:
The job is extremely important. That's all there is to it. It's particularly important since I can enjoy the social aspect and be stimulated. It definitely means that I enjoy it a great deal. Participant number 7

Third, a sense of purpose and perceptions that the work they did benefited other people in difficult situations added to motivation and work satisfaction:

... apart from working to pay for food and rent, work is definitely a major driving force for the social side of things, allowing you to feel that you can make a difference. Participant number 8

\section{Supporting structures}

Three supporting structures were identified as especially important to enable work despite a chronic health condition. These were support from superior, support from healthcare agencies and support from the social insurance fund.

Support from superiors was in most cases initiated only after the participant had made such a demand. The support consisted of organising work and help with task shifting. Support from the company's occupational healthcare provider was usually initiated by the employer and could include workplace interventions and a longterm rehabilitation plan. Study participants said that this support contributed to peace of mind, reduced anxiety and meant less time off sick.

It was the prompt support I got from my boss and the company's healthcare team. I would say that it was completely down to the help I got and my own attitude that I could go back to work. Participant number 6

Support from health services, which included different healthcare agencies, such as primary care, specialists and the occupational healthcare providers. Suitable medical and behavioural treatment, guided physical activity, physical treatment, knowledge of self-care and individual training, assistance with getting their own office and, to a certain degree, advice about job scope were some of the forms of support provided. Support from the healthcare agencies was considered to be just as vital for those who had received it as it was perceived as a major loss for those who had not. Some said that the company's occupational healthcare provider was hard to access, and there was uncertainty regarding which type of support they could give. Others mentioned the contribution made by the company's healthcare team, with support for a change in behaviour in relation to achieving an activity balance. The participants said that contact with the regular healthcare system was a private thing and cooperation with other supporting structures did not occur.

Support from the social insurance fund, in cooperation with the employer, seemed to some study participants to be a success factor in terms of finding a sustainable work situation. The cooperation was usually initiated by the 
insurance fund and also by the employee. The support measures implemented were a long-term rehabilitation plan, work training, an opportunity to try out new work tasks and a gradual increase in working hours as the study participants' well-being improved. This helped these study participants to find a sustainable solution and achieve a balance in their working hours and tasks. One interviewee with recurring depression, for whom gradual return-to-work was incremental for success said that:

One of the best sources of support came from the social insurance fund and my employer, who didn't push too hard. Participant number 10

\section{DISCUSSION}

The analysis process highlighted five main themes that influence the continuation of the study participant's work-life, even when suffering from chronic health conditions. Major emphasis has been placed on describing factors that enable rather than hindering work. The study's results show with good consensus that factors enabling people to continue work while suffering a chronic health condition include adapting the work situation by complete or partial task-shifting and provision of physical aids. Other themes found are adaptation of individual behaviour related to work and personal life. We also found that the study participants' view of their condition, their confidence in their own ability and motivation to work also were significant factors contributing to both wanting and being able to work. In this study, all participants felt that they could (if they wanted to) influence both their work situation and work environment to a certain degree, a finding that highlights the importance of agency and adjustment latitude.

Young et $a l^{13}$ criticised existing disability research for a tendency to only distinguish between those working and those out of work. Instead they propose that focus should be on differentiating between those who are still transitioning to stable employment and those who have achieved vocational stability. ${ }^{13}$ The group studied here can all be said to have achieved vocational stability, although some are still in a transitional stage. Most research on chronic health condition and work has a focus on the return-towork process, which happens early in a transitional stage.

Loisel et $a l^{14}$ proposed a new paradigm for what they called disability prevention which, in turn, was defined as prolonged absence from work. ${ }^{14}$ Within this paradigm, causes to disability were found within four systems: the worker with the symptoms, the workplace, the healthcare system and the compensation system. Our results show that these causes also seem to be evident when it comes to understanding reasons for vocational stability among those with chronic health condition. There are few studies on retention of workers with chronic disease at work, ${ }^{15}$ and the main contribution of our study is that it, reassuringly enough, indicates that the same factors are in play for 'return-to-work' as 'stay-at-work' for employees with chronic disease.

Adaptation measures in the workplace offer relevant support with a positive impact on work ability. ${ }^{16} 17$ Employers are required by law to adapt working conditions to individuals' different physical and mental requirements. ${ }^{18}$ Possible reasons for failing to or delaying adaptations are frequent changes in management, ignorance of the issue among employers or study participants deciding not to mention any support requirements. Norstedt ${ }^{19}$ highlights difficulties that people who have hidden functional impairments have about mentioning this in their workplaces as their perceptions are that it can result in adverse consequences. ${ }^{19}$ Other studies have suggested that dialogue between the employer and employee, and tailored work-related interventions may be helpful. ${ }^{7}$ This is confirmed in this study where the study participants who decided to talk to their employer about this matter have perceived that they have received good adaptations and support.

Lifestyle factors, such as physical activity, other leisure activities and behavioural changes in order to attain a good work-life balance, seemed to play a significant role to stay at work despite health issues. Physical activity in particular seemed to be a strong contributory factor in preventing further deteriorating of the participants' health, thereby improving their work ability, which tallies with the findings from other research studies. ${ }^{20}$

Confidence in one's own ability, often labelled 'self-efficacy' or 'coping', plays an important role in how individuals handle specific situations and is a determinant of their ability to influence their situation. ${ }^{21}$ The group of informants in the present study held a pragmatic view of their options in life and generally showed broad acceptance of their situation and a high level of confidence in their own ability. From an outsider's perspective, their health status did not seem to correlate with their perceived health or their self-reported work ability, highlighting the importance of a holistic approach tailored for the individual in order to retain workers with chronic disease while also maintaining productivity as proposed in previous research by others. ${ }^{15}$ Confidence in their own ability could also have been reinforced by the generally high level of adjustment latitude, which is well known to be associated to a lower risk of sick leave. ${ }^{22}{ }^{23}$ It also aligns well with findings that expanded job control could be an important way to counteract the effect of decreased work ability on productivity. ${ }^{24}$

Work motivation was high for all respondents, irrespective of health status. Although factors outside the workplace are important, our results suggest that it should be possible to develop and evaluate interventions aimed at maintaining work motivation, especially intellectual stimulation, social cohesion and sense of purpose. It seems important to help workers to maintain and cultivate a sense of coherence ${ }^{25}$ at the workplace, where comprehensibility, manageability and meaningfulness can contribute to the individual's health. In order to achieve successful 
work adaptations and maintain good social work environment, support, especially from superiors who contribute to creating opportunities for a longer working life and have a positive impact on workers' health. ${ }^{26}{ }^{27}$ Some participant had received support from their superior in different ways, including finding suitable work tasks and adapting the way of working. Study participants who additionally received support from the healthcare team and social insurance fund acknowledged that this was a further boosting factor. These results are in line with findings by others, that employers who adopt a structured approach to rehabilitation, cooperate with other agencies and have strong leadership functions have healthier employees. ${ }^{28}$ The study participants felt a general lack of support from the healthcare agencies, which is common among people with a chronic health condition. ${ }^{29}$ National guidelines indicate the importance of the support provided by healthcare agencies in terms of rehabilitation by offering continuous, coordinated care to people with a chronic health condition of working age, enabling them to cope with working life. ${ }^{30}$ Varekamp $e t a \hat{l}^{31}$ also highlight the importance of the overlap between the provision of healthcare and rehabilitation geared towards working life. $^{31}$

\section{Strengths and limitations}

The trustworthiness of our study is primarily established through the credibility of the research methods we applied. ${ }^{32}$ The choice of semistructured, in-depth interviews was to give greater scope for individuals to talk about their experiences and thoughts. It is regarded as a flexible and tried-and-trusted method for gathering data in the field of healthcare research. ${ }^{33}$ Interviews was held by the same author to ensure the same procedure. No field notes were taking during the interviews to enable an active and attentively listening. Those were important steps to avoid self-understanding and interpretation and to achieve credibility in the findings. The study author's experience of working in the field of work-related rehabilitation and of working for the same employer as the study participants is mainly considered to be a strength as it made iterative questioning possible, that is, ask follow-up questions and go into greater depth on various questions.

A limitation, both with regards to establishing credibility and transferability, is that this study is limited to a small number of participants and a single employer. Aspects of work and chronic disease that could be present among employees in, for example, private sector or manual work have not been investigated in this study. In spite of the small numbers, the data material gathered is considered to have achieved saturation, based on the study's questions. This was indicated by a large level of consensus and recurrently similar answers within the question areas. This was true in spite of different genders, professional categories and workplaces featuring in the study. Although the results should be interpreted with caution, they are consistent with previous research. ${ }^{35783134}$ The dependability and confirmability of this study was assured through close adhesion to COREQ guidelines ${ }^{11}$ and detailed reporting of methodology in order to enable the reader to make a critical appraisal of our study.

\section{CONCLUSIONS}

This study found that factors enabling workers with chronic health conditions to work include early adaptation of the work situation, lifestyle conditions, confidence, motivation and support. Similar to what has been shown in disability research, our results indicate that stakeholders such as the individual, the work place, the compensation system and the healthcare system can support ability and motivation to work among those with a chronic health condition. There is a need for more studies of conditions enabling people with health conditions to remain in work. As this study only included civil servants, future studies should also focus on what enables work among manual workers with a chronic health condition.

Acknowledgements We would like to sincerely thank all the study participants who took the time to take part and talk about their experiences. We hope that we have done justice to the information you provided. We would also like to thank the employers for agreeing to participate and to those who helped with sending out the study invitations.

Contributors The study was conceived by $\mathrm{CH}$ and TB. The study protocol was developed by $\mathrm{CH}, \mathrm{ALN}$ and TB. The interviews were recorded, transcribed verbatim by $\mathrm{CH}$ and analysed by $\mathrm{CH}$ under supervision from ALN. The interpretation of the findings was done by all authors. The first draft of the manuscript was done by $\mathrm{CH}$. All subsequent drafts were commented upon and revised by all authors. The submitted version of the manuscript was approved by all authors.

Funding This Study was supported by the Swedish Research Council for Health, Working Life and Welfare, FORTE.

Disclaimer The employer was not involved in designing and analysing the study and had no influence over the study's conclusions.

Competing interests $\mathrm{CH}$ works at the Swedish Public Employment Service. The other authors state that they have no conflicts of interest or objections.

Patient consent Obtained.

Ethics approval The study has been approved by the Regional Ethical Review Board in Stockholm, reference number 2016/2105-31/5.

Provenance and peer review Not commissioned; externally peer reviewed.

Data sharing statement This study does not include any data that could be shared.

Open Access This is an Open Access article distributed in accordance with the Creative Commons Attribution Non Commercial (CC BY-NC 4.0) license, which permits others to distribute, remix, adapt, build upon this work non-commercially, and license their derivative works on different terms, provided the original work is properly cited and the use is non-commercial. See: http://creativecommons.org/ licenses/by-nc/4.0/

(C) Article author(s) (or their employer(s) unless otherwise stated in the text of the article) 2018. All rights reserved. No commercial use is permitted unless otherwise expressly granted.

\section{REFERENCES}

1. de Jong PR. Sickness, disability and work: breaking the barriers-a synthesis of findings across OECD countries-by OECD. Int Soc Secur Rev 2011;64:103-4.

2. Arbetsmiljöverket. The work environment 2013, 2014.

3. Hasselhorn HM, Apt W. Understanding employment participation of older workers: Creating a knowledge base for future labour market challenges. Berlin, 2015. 
4. Sverige, Statistiska centralbyrån. Situationen på arbetsmarknaden för personer med funktionsnedsättning 2015 / The labour market situation for people with disabilities 2015 / Statistics Sweden. Stockholm: Statistiska centralbyrån (SCB), 2016.

5. Boot CR, van den Heuvel SG, Bültmann U, et al. Work adjustments in a representative sample of employees with a chronic disease in the Netherlands. J Occup Rehabil 2013;23:200-8.

6. Solem Pere, Syse A, Furunes T, et al. To leave or not to leave: retirement intentions and retirement behaviour. Ageing Soc 2016;36:259-81.

7. de Wind A, Geuskens GA, Reeuwijk KG, et al. Pathways through which health influences early retirement: a qualitative study. BMC Public Health 2013;13:292.

8. de Vries HJ, Reneman MF, Groothoff JW, et al. Factors promoting staying at work in people with chronic nonspecific musculoskeletal pain: a systematic review. Disabil Rehabil 2012;34:443-58.

9. de Jong M, de Boer AG, Tamminga SJ, et al. Quality of working life issues of employees with a chronic physical disease: a systematic review. J Occup Rehabil 2015;25:182-96.

10. Kaye HS, Jans LH, Jones EC. Why don't employers hire and retain workers with disabilities? J Occup Rehabil 2011;21:526-36.

11. Tong A, Sainsbury P, Craig J. Consolidated criteria for reporting qualitative research (COREQ): a 32-item checklist for interviews and focus groups. Int J Qual Health Care 2007;19:349-57.

12. Braun V, Clarke V. Using thematic analysis in psychology. Qual Res Psychol 2006;3:77-101.

13. Young AE, Roessler RT, Wasiak R, et al. A developmental conceptualization of return to work. J Occup Rehabil 2005:15:557-68.

14. Loisel P, Durand MJ, Berthelette D, et al. Disability Prevention. Dis Manag Health Outcomes 2001;9:351-60.

15. Leijten F, van den Heuvel S, Geuskens G, et al. How do older employees with health problems remain productive at work?: a qualitative study. J Occup Rehabil 2013;23:115-24.

16. Franche RL, Cullen K, Clarke J, et al. Workplace-based return-towork interventions: a systematic review of the quantitative literature. J Occup Rehabil 2005;15:607-31.

17. Vooijs M, Leensen MC, Hoving JL, et al. Interventions to enhance work participation of workers with a chronic disease: a systematic review of reviews. Occup Environ Med 2015;72:820-6.

18. Arbetsmiljöverket. Arbetsanpassning och rehabilitering AFS 1994:1. Stockholm: Arbetsmiliöverket, 1994.

19. Norstedt M. Att avslöja sina dolda funktionsnedsättningar i arbetslivet. Arbetsmarknad Arbetsliv 2016;22:36-48.
20. Arvidson E, Börjesson M, Ahlborg G, et al. The level of leisure time physical activity is associated with work ability-a cross sectional and prospective study of health care workers. BMC Public Health 2013;13:855.

21. Dehlin O, Hagberg B. Inte hur man har det utan hur man tar det. Läkartidningen 2000;97:430-3.

22. Johansson G, Lundberg I. Adjustment latitude and attendance requirements as determinants of sickness absence or attendance. Empirical tests of the illness flexibility model. Soc Sci Med 2004;58:1857-68.

23. Leijten FR, de Wind A, van den Heuvel SG, et al. The influence of chronic health problems and work-related factors on loss of paid employment among older workers. J Epidemiol Community Health 2015;69:1058-65.

24. van den Berg TI, Robroek SJ, Plat JF, et al. The importance of job control for workers with decreased work ability to remain productive at work. Int Arch Occup Environ Health 2011;84:705-12.

25. Antonovsky A. Unraveling the mystery of health: how people manage stress and stay well: Jossey-Bass, 1987.

26. Krause N, Lynch J, Kaplan GA, et al. Predictors of disability retirement. Scand J Work Environ Health 1997;23:403-13.

27. Searle B, Bright JEH, Bochner S. Helping people to sort it out: the role of social support in the job strain model. Work Stress 2001;15:328-46.

28. Svartengren $\mathrm{M}$, Stoetzer $\mathrm{U}$, Parmsund $\mathrm{M}$, et al. Hälsa och framtid $i$ kommuner och landsting. Stockholm, 2013.

29. Socialstyrelsen. Hälso- och sjukvård vid kroniska sjukdomar: Socialstyrelsen, 2015

30. Government of Sweden. Nationell strategi för att förebygga och behandla kroniska sjukdomar: 2014-2017. Stockholm: Socialdepartementet, Regeringskansliet, 2014.

31. Varekamp I, Verbeek JH, van Dijk FJ. How can we help employees with chronic diseases to stay at work? A review of interventions aimed at job retention and based on an empowerment perspective. Int Arch Occup Environ Health 2006;80:87-97.

32. Shenton AK. Strategies for ensuring trustworthiness in qualitative research projects. Educ Inf 2004;22:63-75.

33. Dicicco-Bloom B, Crabtree BF. The qualitative research interview. Med Educ 2006; 40:314-21.

34. Loisel P, Buchbinder R, Hazard R, et al. Prevention of work disability due to musculoskeletal disorders: the challenge of implementing evidence. J Occup Rehabil 2005;15:507-24. 